\title{
Neural representations of awe: Distinguishing common and distinct neural mechanisms
}

$$
\text { Ryota Takano }{ }^{1,2} \text {, Michio Nomura }{ }^{1}
$$

${ }^{1}$ Graduate School of Education, Kyoto University, Yoshida-Honmachi, Sakyo-ku, Kyoto 6068501, Japan

${ }^{2}$ Japan Society for the Promotion of Science, Tokyo 102-8471, Japan

**This pre-print is the pre-formatted version of a manuscript that has been accepted for publication in Emotion.**

(C) 2020, American Psychological Association. This paper is not the copy of record and may not exactly replicate the final, authoritative version of the article. Please do not copy or cite without authors' permission. The final article will be available, upon publication, via its DOI: 10.1037/emo0000771

Supplementary Material includes: Figure S1 and Tables S1-6.

Acknowledgment: We thank T. Kochiyama for lending his expertise on the analysis of MRI data.

Conflicts of Interest: There are no conflicts of interest. 


\begin{abstract}
Awe is an emotional response to perceptually vast stimuli that transcend one's current frames of reference. The psychological form and function of awe differ between two types: positive-awe, which arises from perceptually aesthetic experiences (e.g., the beauty of nature, spiritual experiences, or the virtue of a leader), and threat-awe, which is triggered by threatening stimuli (e.g., natural disasters, wrathful god, or a leader's coercive charisma). Here, using functional magnetic resonance imaging, we investigated common and distinct neural responses to experiences of positive- and threat-awe, elicited by watching awe-inspiring videos. We found that both awe experiences deactivated the left middle temporal gyrus (MTG) in contrast to control conditions (positive-awe vs. amusement; threat-awe vs. fear), which suggest that awe experiences generally involve the "schema liberation" process since the left MTG plays a critical role in matching existing schema to events. In addition, positive-awe was associated with increased functional connectivity between the MTG and the anterior/posterior cingulate cortex, which are associated with the aesthetic reward process, and the supramarginal gyrus (SMG), which is involved in the self-other representation. Threat-awe was associated with increased functional connectivity between the MTG and amygdala, which detects and processes threat stimuli, as well as between the amygdala and SMG. These findings suggest that the neural mechanisms underlying the complex psychological processes of awe vary as a function of the type of awe. The implications of these results regarding our understanding of the neural basis of awe and the future directions of human social cognition research are discussed.
\end{abstract}

Keywords: awe, positive-awe, threat-awe, functional magnetic resonance imaging 


\section{Neural representations of awe: Distinguishing common and distinct neural mechanisms}

Awe has been defined as an emotional response to perceptually vast stimuli that transcend one's current frames of reference (Keltner \& Haidt, 2003). The emotional concept of awe has been studied for a long time in philosophy, sociology, and religion (Keltner \& Haidt, 2003), and more recently in psychology, where it has attracted attention (e.g., Bai et al., 2017; Gordon et al., 2017; Piff, Dietze, Feinberg, Stancato, \& Keltner, 2015). An important finding is that there appear to be two types of awe that have distinct effects on human cognition and social behaviors: positive-awe, which arises by being exposed to perceptually aesthetic experiences such as beautiful nature, spiritual phenomena, and the virtue of charismatic leader; and threatawe, which is triggered by threatening stimuli such as natural disasters, a punitive God, and a leader's coercive charisma (Gordon et al., 2017). While several studies investigated the psychological structures and functions of awe, little is known about its neural bases. However, previous studies suggested that distinct neural mechanisms underlie the various functions of the two types of awe (Gordon et al., 2017). Therefore, the present study aimed to investigate the common and distinct neural mechanisms underlying these two types by examining neural responses during awe experiences using functional magnetic resonance imaging (fMRI). The results of this investigation have valuable implications regarding the psychological concepts of awe.

Based on theoretical and philosophical underpinnings, it has been proposed that awe consists of two common features: a perception of vastness, which is the sense that one has encountered something immense in size, social status, or complexity; and the need for accommodation, which is the process by which a person revises one's mental schemas or creates a new one to account for the deviation between the stimuli and one's current 
understanding of the world (Gordon et al., 2017; Keltner \& Haidt, 2003). Furthermore, awe alters the content of the self-concept by shifting attention away from the self towards vast stimuli (Shiota, Keltner, \& Mossman, 2007). The experience of awe diminishes self-focused attention and increases feelings of being small or insignificant (Bai et al., 2017; Piff et al., 2015). In a study of emotion narratives, participants' self-reported experiences of awe, but not of other positive emotions (e.g., love and gratitude), were uniquely associated with reports of feeling “small” (Campos, Shiota, Keltner, Gonzaga, \& Goetz, 2013). This research suggests that the sense of a smaller self is an important psychological process of awe (Shiota et al., 2007).

A previous relevant study investigated the relationship between individual differences in dispositional awe (an emotional disposition pertaining to one's latent tendency to experience awe) and brain structural parameters (Guan, Xiang, Chen, Wang, \& Chen, 2018). The researchers found that individual differences in dispositional awe are negatively correlated with three brain regions; the left middle temporal gyrus (MTG), the anterior cingulate cortex (ACC), and the posterior cingulate cortex (PCC). Their findings suggest that the MTG is instrumental regarding the detection and resolution of incongruity during awe experiences, as this area is associated with humor comprehension involving gaps and incongruences between information (Bartolo, Benuzzi, Nocetti, Baraldi, \& Nichelli, 2006), and that the ACC and PCC are associated with the reward-related process of awe. Guan et al. (2018) conducted a study to provide evidence for a structural neural basis of awe, focusing on the positive form of awe (example item for dispositional awe: "I see beauty all around me"; Shiota, Keltner, \& John, 2006). The next step in this research progression would be to investigate how these identified brain regions respond to awe-inspiring stimuli and whether or not and how the response differs 
between positive- and threat-awe. Therefore, in the present study, we examined the functional neural responses of participants whilst they watched videos of positive- or threat-awe stimuli in the fMRI scanner.

Although brain structural evidence does not always predict functional imaging findings, according to the findings of Guan et al. (2018), the neural mechanisms of awe involve the left MTG, ACC, and PCC. The central feature of awe is thought to be a vast stimulus that cannot be assimilated into current knowledge structures (Keltner \& Haidt, 2003). The left MTG, especially the posterior area, plays a key role in matching an existing knowledge framework to an event (Davey et al., 2016). For example, Davey et al. (2015) found that transcranial magnetic stimulation, which can inhibit a small area of the brain below the coil, to the left MTG disrupted thematic judgments for weak associations between concepts (e.g., a picture of slipper with a word "hospital"). Consistent with these researches, Guan et al. (2018) suggested that the left MTG is involved in detecting and solving incongruities in the process of experiencing awe. Therefore, we predicted that the left MTG would be involved in awe experiences regardless of the type of awe (i.e. a common neural mechanism), playing a central role in the psychological meaning of awe.

Experiences of positive-awe involve a perception of aesthetics or beauty (Silvia, Fayn, Nusbaum, \& Beaty, 2015). In addition, it is typically considered a positive emotion, which is strongly associated with reward (Shiota et al., 2006). The cingulate cortex serves as a gateway among cortical regions that integrate reward-related information (Hayden \& Platt, 2009). For example, the ACC is associated with the reward process during an aesthetic judgment of landscape stimuli (Kawabata \& Zeki, 2004). Furthermore, PCC activity reflects the subjective 
value of the reward (Levy \& Glimcher, 2011). Thus, we predicted that the ACC and PCC would be key areas involved in positive-awe experiences.

In contrast, although no neuroimaging study has focused on threat-awe, which is characterized by the perception of a threat (Gordon et al., 2017), we predicted that the amygdala would be involved in threat-awe experiences since it plays an important role in detecting and processing various threat-related stimuli (e.g., Öhman, 2005; Rodrigues, LeDoux, and Sapolsky, 2009). The amygdala activates the sympathetic nervous system, which facilitates rapid behavioral responses. Gordon et al. (2017) indicated that greater skin conductance and higher heart rate were associated with higher ratings of threat during an awe experience. In addition, the amygdala sends signals to other regions that are responsible for appraisal or regulatory aspects of emotional responses (e.g., Lindquist, Wager, Kober, Bliss-Moreau, \& Barrett, 2012; Nomura et al., 2004; Whalen, 2007). Therefore, we expected the amygdala to be involved in threat-awe experiences.

Similar to admiration and compassion, awe is defined as a self-transcendent emotion, which encourages one's feeling of a connection to others (Stellar et al., 2017). For example, the supramarginal gyrus (SMG), which is located in an anterior part of the temporoparietal junction (TPJ), is engaged during experiences of admiration and compassion (Immordino-Yang, McColl, Damasio, Damasio, 2009), consistent with previous findings that the TPJ facilitates the recognition of another's perspective (e.g., Decety \& Sommerville, 2003). Therefore, we hypothesized that the SMG would be involved in positive-awe experiences, along with the left MTG. However, considering the evidence that self-transcendent emotions, such as compassion, can also be experienced as a negative state (Stellar et al., 2017), the SMG could also play an important role in the experience of threat-awe. Given that positive- and threat-awe have 
different effects on social attitudes (Sawada \& Nomura, 2020), we further hypothesized that the SMG would be differently involved in awe-inspiring experiences, depending on the type of awe.

In summary, in the present investigation, we tested the following four hypotheses (see Table 1):

Hypothesis 1: Both positive- and threat-awe experiences would be associated with the left MTG.

Hypothesis 2: Positive-awe experiences would be associated with the ACC and PCC.

Hypothesis 3: Threat-awe experiences would be associated with the amygdala. Hypothesis 4: The SMG would be differently involved in experiences of awe, depending on their types of awe.

Table 1

Summary of brain areas that would be associated with positive- and threat-awe experiences and their predicted roles.

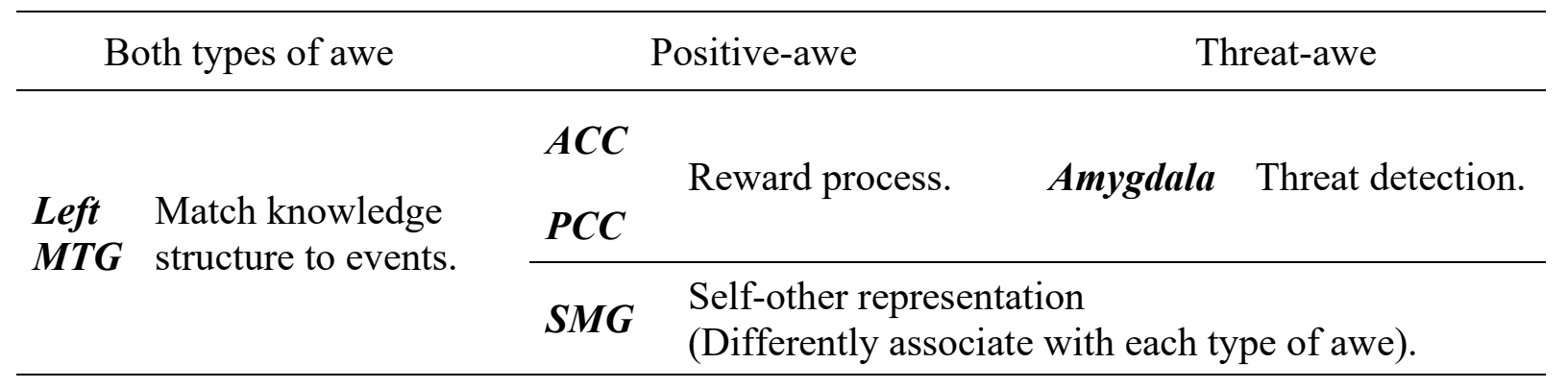

Note: $\mathrm{MTG}=$ Middle Temporal Gyrus, $\mathrm{ACC}=$ Anterior Cingulate Cortex, $\mathrm{PCC}=$ Posterior Cingulate Cortex, SMG = Supramarginal Gyrus. 


\section{Materials and Methods}

\section{Participants}

Thirty-eight right-handed Japanese university students (aged 20-27 years), with normal or corrected vision, participated in this study. After screening for excessive head motion during fMRI (>3 mm), 36 participants were included in the analyses (18 males and 18 females, mean age $=22.42$ years, $S D=1.59)$. The local institutional review board approved this study, and all participants provided written informed consent prior to participating in the study. The sample size was based on a previous study that examined individual differences in neural responses to emotional video stimuli (e.g., Straube et al., 2010; $N=40$ ). The effect size of the correlation between subjective anxiety ratings and brain activation was $r=0.50$, which has sufficient analytic power, $\beta=.94$ (Straube et al., 2010, p. 41).

\section{Stimuli}

Per previous studies (Gordon et al., 2017; Piff et al., 2015), we compared both positiveand threat-awe responses to a non-emotional control state (neutral), as well as to general positive and negative emotional states (amusement and fear). This experimental design assists the revealing of awe-specific neural responses by strictly controlling for valence. During each of two scans, participants watched five 120-s video clips from inside the MRI scanner. In total, there were two video clips for each of the five emotional conditions. Positive-awe clips comprised nature clips from the BBC's Planet Earth series and starry skies recorded with time-lapse cameras, which have often been used in studies of awe (e.g., Piff et al., 2015). Threat-awe clips comprised scenes of natural disasters, such as volcano eruptions, tornados, lightning storms at night, and avalanches (modified from Gordon et al., 2017). Amusement clips comprised nature clips from the BBC's comedic series, Walk on the Wild Side, which show animals in their natural 
habitats acting in humorous ways (Piff et al., 2015). Fear clips comprised scenes from the movies, The Shining and The Blair Witch Project, which were obtained from a standardized database of brief video clips (Schaefer, Nils, Sanchez, \& Philippot, 2010) and have been used regularly in fMRI studies (Straube et al., 2010). Neutral clips comprised company promotional videos. All video clips were edited to be exactly $120 \mathrm{~s}$ in length and encoded with $1280 \times 720$ resolution.

\section{Self-reported validation of stimuli}

To validate our expected results, we conducted two pilot surveys. Adults (pilot study 1, $N$ $=27$; pilot study $2, N=19$ ) watched each video and reported their emotions, valence, and arousal on 9-point scales, and familiarity on a 7-point scale. As predicted, the mean awe scores were higher for positive- and threat-awe videos than for videos of other conditions (positive-awe: mean: $5.52 \pm S D$ : 1.47 ; threat-awe: $5.51 \pm 1.97$; other conditions: $<3.50 \pm<1.68)$. In addition, the mean scores of amusement $(5.52 \pm 2.23)$ and fear $(6.71 \pm 2.27)$ were highest in the amusement and fear conditions, respectively. The results of these pilot studies and the video stimuli (except for neutral videos) are available at https://osf.io/nxy $7 \mathrm{a} /$.

\section{Procedure}

We used a block design in the two functional scans, with five emotional blocks in each scan (positive-awe, threat-awe, amusement, fear, and neutral; see Fig. 1). Within a scan, the set of the five videos was fixed. However, the order of the sets and emotional blocks were counterbalanced across participants. During the first rest block, a fixation cross was shown for 15 $\mathrm{s}$, followed by the task instructions, which were displayed for $5 \mathrm{~s}$. In the remaining rest blocks, a fixation cross was shown for 25 s. Participants watched the videos, which were projected onto a 
white screen through a mirror mounted on the head coil, and listened to the soundtrack through MRI-compatible earphones or headphones.

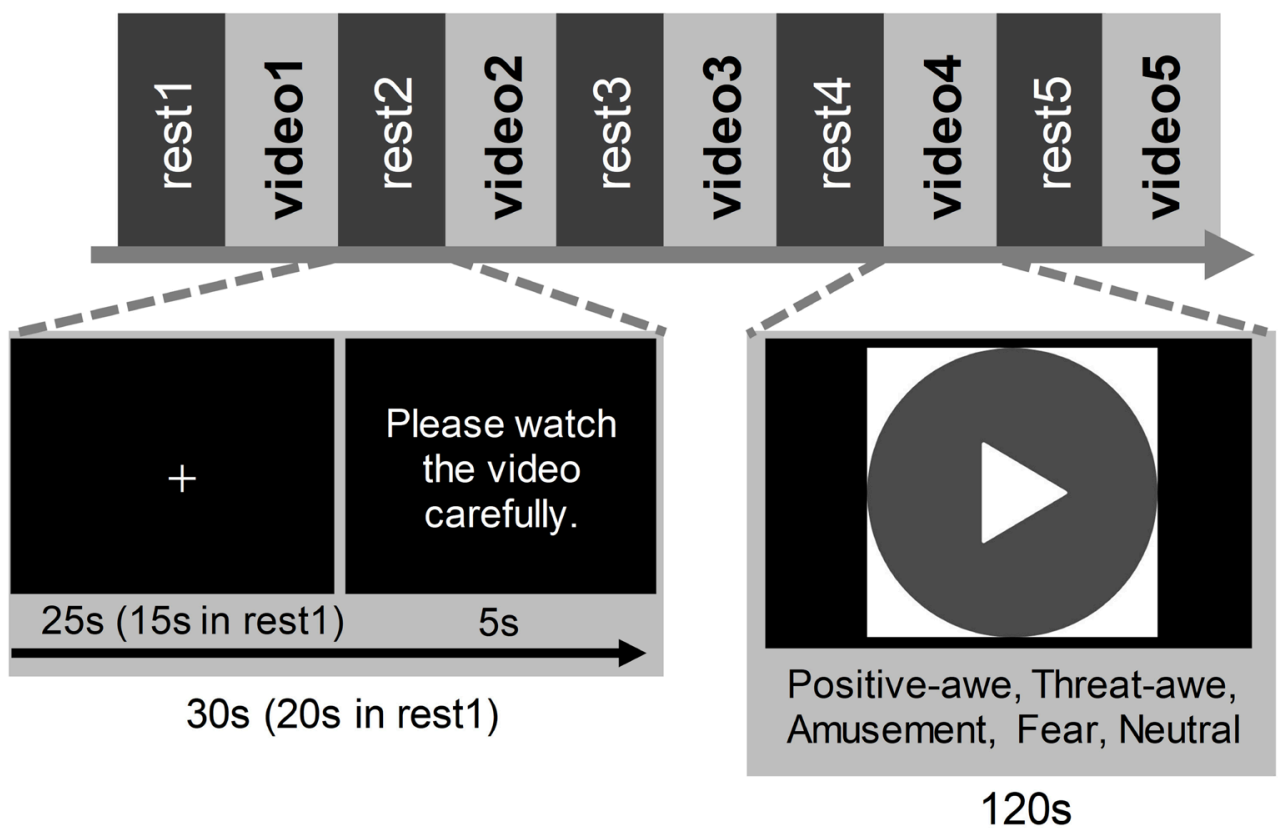

Figure 1. The sequence for one scan in our experimental paradigm. The fMRI experiment consisted of two functional scans, each lasting 12 min $20 \mathrm{~s}$. Please refer to the online article for the color version of this figure.

After scanning, the participants re-watched the video clips outside the scanner and reported the extent to which they experienced thirteen emotional states, including awe [mean scores of $i k e i$, ifu (awe in Japanese), wonder, and sublime; $\alpha$ s > .72; Gordon et al., 2017], fear, amusement, etc., using 9-point Likert scales ( $1=$ not at all, 9 = extremely) (details are available in Table S2). The order of the ten video clips was randomized. In addition, to assess whether they felt a small sense of self, participants were presented with a series of seven circles and asked to select options that best represented their perceived self-size (Figure S1; Bai et al., 2017). 


\section{fMRI Data Acquisition}

All MR images were acquired using a Siemens 3.0 Tesla Verio scanner with a 32-channel phased-array head coil, located at the Kokoro Research Center, Kyoto University. Structural data were acquired with a high-resolution magnetization-prepared rapid acquisition gradient-echo T1weighted sequence [208 axial slices; no gap between slice acquisition; repetition time (TR) $=2250$ $\mathrm{ms}$; echo time $(\mathrm{TE})=3.51 \mathrm{~ms}$; field of view $(\mathrm{FOV})=256 \mathrm{~mm}$; matrix $=256 \times 256$; voxel size: 1.0 $\times 1.0 \times 1.0 \mathrm{~mm}$; flip angle $=9^{\circ} \mathrm{]}$. Functional data were acquired with a gradient-echo echo-planar imaging sequence [39 axial slices; slice thickness $=3.0 \mathrm{~mm}$ with a $25 \%(0.75 \mathrm{~mm})$ slice gap; $\mathrm{TR} / \mathrm{TE}=2500 / 30 \mathrm{~ms} ; \mathrm{FOV}=192 \mathrm{~mm} ;$ matrix $=64 \times 64$; voxel size: $3.0 \times 3.0 \times 3.0 \mathrm{~mm}$; flip angle $\left.=90^{\circ}\right]$

\section{fMRI Data Pre-processing}

The fMRI data were analyzed using SPM12 (Wellcome Department of Imaging Neuroscience, London, UK), implemented in MATLAB R 2018a (Math Works, MA). Before data processing and statistical analyses, we discarded the first four volumes to allow for $\mathrm{T} 1$ equilibration. All remaining volumes were slice-timing corrected, realigned to the mean volume to correct for head motion, normalized and resliced to $2 \times 2 \times 2 \mathrm{~mm}$ voxels in a common brain space [Montreal Neurological Institute (MNI) T1 template], and smoothed with an $8 \mathrm{~mm}$ fullwidth, half-maximum Gaussian filter. Low-frequency noise was removed by applying a high-pass filter (cutoff period $=128 \mathrm{~s}$ ) to the fMRI time series at each voxel.

\section{Behavioral Data Analysis}

Statistical analyses of the behavioral data were conducted in IBM SPSS Statistics 22.0 (SPSS Inc., Chicago, IL, USA). One-way repeated-measures analyses of variance (ANOVAs) 
were conducted to assess differences among the five emotional conditions in terms of the emotional state ratings and feelings of a small self.

\section{fMRI Data Analysis (Univariate Analysis)}

We first conducted univariate analyses using the general linear model (GLM) in SPM12. To examine the neural responses specifically associated with positive-awe, threat-awe, and both awe experiences, three contrast images were created for each participant: 1) a contrast image for positive-awe blocks (vs. amusement blocks), 2) a contrast image for threat-awe blocks (vs. fear blocks), and 3) a contrast image for both awe blocks [vs. control blocks (amusement and fear)]. We additionally created three contrast images for positive-awe, threat-awe, and awe blocks versus neutral blocks (for results, see Tables S3-5). These contrast images were submitted to a secondlevel analysis.

In the second-level analysis, whole-brain activation maps were created. Individual contrast maps were included in a group-level analysis using one-sample t-tests. For the univariate analyses, the statistical threshold was set at voxel-wise $p<0.001$ (uncorrected) and cluster-wise $p<0.05$ [family wise error (FWE)-corrected for multiple comparisons].

\section{fMRI Data Analysis (Functional Connectivity Analysis)}

Seed-to-region of interest (ROI) functional connectivity (FC) analyses were performed using generalized psychophysiological interaction (gPPI) models, implemented in the CONN toolbox v18.a (Whitfield-Gabrieli and Nieto-Castanon, 2012), which is available for resting-state data as well as task-related designs (Breukelaar et al., 2018; Pozzi et al., 2019). The seed region for the gPPI analysis was chosen based on the univariate findings, which showed a strong relationship between the experience of awe and left MTG deactivation. To investigate the FC of the left MTG, we selected eight ROIs based on previous studies (Gordon et al., 2017; Guan et al., 
2018; Immordino-Yang et al., 2009; Table S1): bilateral amygdala, ACC, PCC, and bilateral anterior and posterior supramarginal gyrus (SMG). A denoising procedure was applied to remove the effects of confounding factors (main task effects, white matter, cerebrospinal fluid, and motion). The signal was high-pass filtered above $0.008 \mathrm{~Hz}$ to retain higher-frequency information related to the task (Wierzba et al., 2018). The same three contrasts as those in the univariate analyses were created for the PPI. For the FC analyses, the two-sided statistical threshold was set at $p<0.05$, false-discovery rate (FDR)-corrected for multiple comparisons. 


\section{Results}

\section{Behavioral Results}

Repeated-measure ANOVAs revealed significant differences among emotional conditions, $F S(4,140)>27.29, \eta_{p}^{2}>0.44, p s<.001$ (Fig. 2A \& 2B). Participants felt significantly more awe, and a smaller sense of self in both awe conditions than in other conditions, $|t s|(35)>3.15,|d s|>0.74, p s \leq .01$. In addition, participants felt more fear in the fear condition than in other conditions, $|t s|(35)>8.26,|d s|>1.55$, ps $<.001$, and more amusement in the amusement condition than in other conditions, $|t s|(35)>5.78,|d s|>1.32$, ps $<.001$. Other differences in the ratings of the emotional response and a small sense of self emerged as well (Table S2).
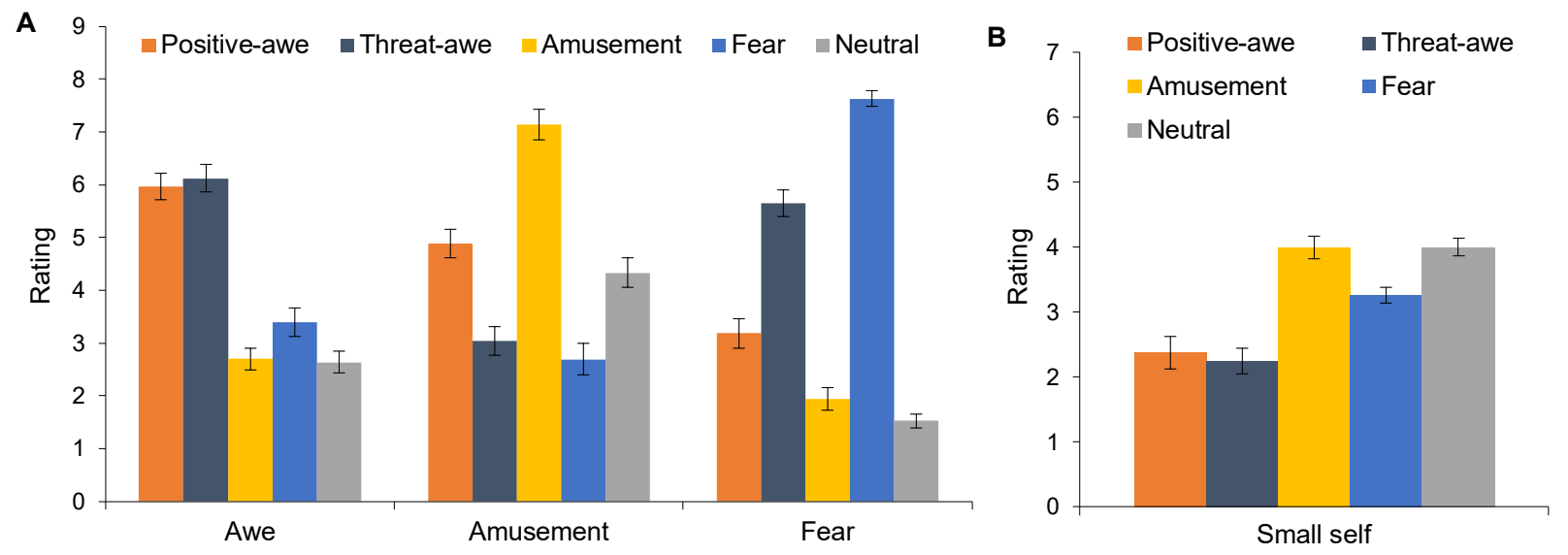

Figure 2. Mean (A) emotional ratings (awe, amusement, and fear) and (B) ratings of a small sense of self are shown for each emotional condition. Error bars represent standard errors. See the online article for the color version of this figure.

\section{fMRI Results (Univariate Analysis)}


In keeping with Hypothesis 1, the awe vs. control contrast revealed decreased activation in the left MTG for both awe conditions relative to that in the control conditions (center at MNI coordinates $x=-46, y=-62, z=4$; Fig. 3). Almost the same cluster was observed for the positive-awe vs. amusement contrast (center at MNI coordinates $x=-50, y=-66, z=4$; Table S4), but not for the threat-awe vs. fear contrast (Table S5). In addition, there seems to be differences in parameter estimates of the left MTG for positive-awe and threat-awe condition (see Fig. 3B). Therefore, to further investigate whether this left MTG cluster was less active in both the positive- and threat-awe conditions and this deactivation differs between positive- and threat-awe conditions, we performed ROI analyses for the contrasts of positive-awe vs. amusement, threat-awe vs. fear, and positive-awe (-amusement) vs. threat-awe (-fear), using 6 mm spheres focused on the center of the left MTG cluster from the awe vs. control contrast (note that these were additional and confirmatory analyses). The ROI analyses were performed using Marsbar software (http://marsbar.sourceforge. net/). We found that the left MTG activity was significantly decreased in both positive- and threat-awe conditions compared to that in the respective control conditions (FWE-corrected cluster-level $p<0.05$; Table S6). In addition, this deactivation is more prominent in the positive-awe compared to the threat-awe conditions. Thus, we used this left MTG cluster (a 6-mm sphere) as the seed region in the subsequent FC analyses. Other regions of (de)activation for the three contrasts also emerged (Table S3-5). 
A Positive-awe and Threat-awe < Amusement and Fear
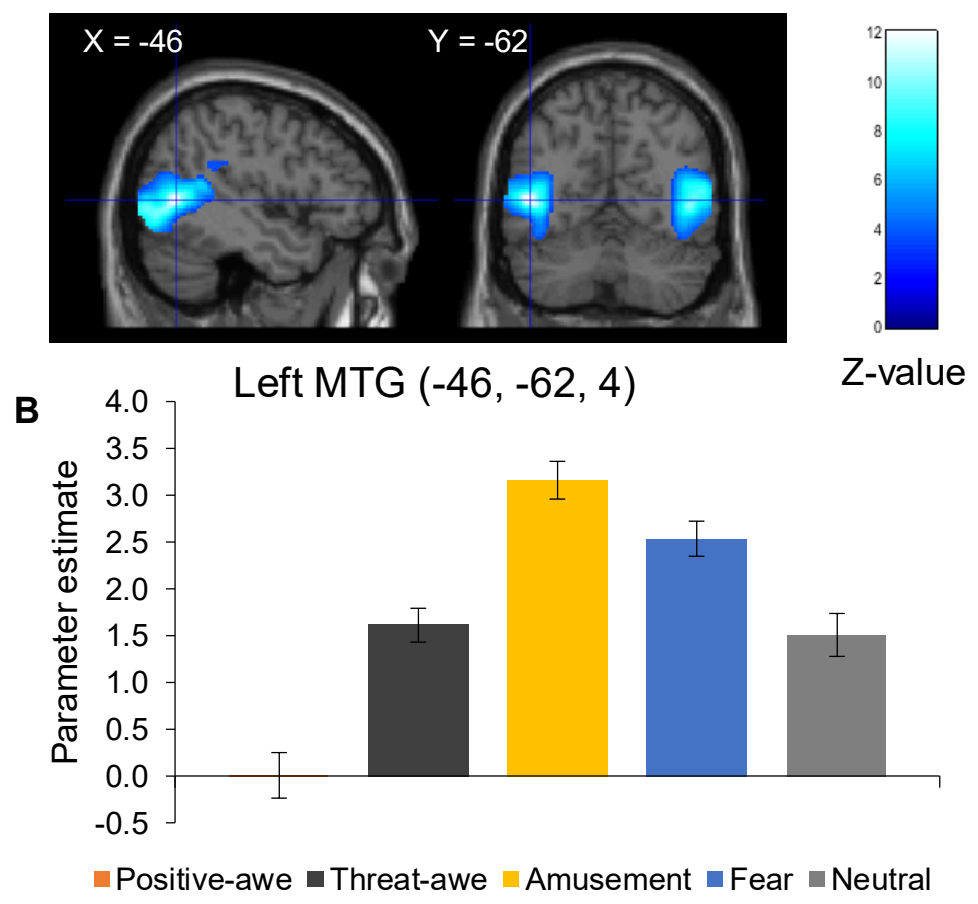

Figure 3. Brain activations related to the experience of positive- and threat-awe. (A) Decreased brain activations were observed in the positive- and threat-awe conditions relative to that in the amusement and fear conditions. A higher intensity of blue reflects greater deactivation during the positive- and threat-awe conditions. (B) Bar chart showing lower activity in the left middle temporal gyrus (MTG) in the awe (positive- and threat-awe) conditions than in the control (amusement and fear) conditions ( $p<0.05$, FWE corrected). Error bars represent standard errors. Please refer to the online article for the color version of this figure.

\section{fMRI Results (functional connectivity analysis)}

None of the evaluated ROIs had significantly stronger functionally connectivity with the left MTG in the awe conditions than in the control conditions, when both conditions were considered together. However, consistent with Hypothesis 2, the positive-awe vs. amusement contrast showed that the positive-awe condition elicited stronger FC between the left MTG and 
the ACC and PCC compared to that in the amusement condition (Fig. 4A). In contrast, consistent with Hypothesis 3, the threat-awe vs. fear contrast indicated that the FC between the left MTG and left amygdala was higher in the threat-awe condition than in the fear condition (Fig. 4B). Since we did not find any significant FC changes between the left MTG and SMG, we conducted two additional and exploratory seed-to-ROI analyses. Firstly, we examined whether the left MTG was functionally connected with the SMG at an uncorrected threshold ( $p$-value $<0.05)$. In keeping with Hypothesis 4, the results showed that the FC between the left MTG and right anterior SMG (aSMG) was greater in the positive-awe condition than in the amusement condition (Fig. 4A). Secondly, we conducted FC analyses that defined the left amygdala as the seed region $(p<0.05$, FDR corrected), and found that the FC between the left amygdala and right aSMG was greater in the threat-awe condition than in the fear condition, in line with Hypothesis 4 (Fig. 4B). All significant FC results remained when the effect of the neutral condition was controlled.
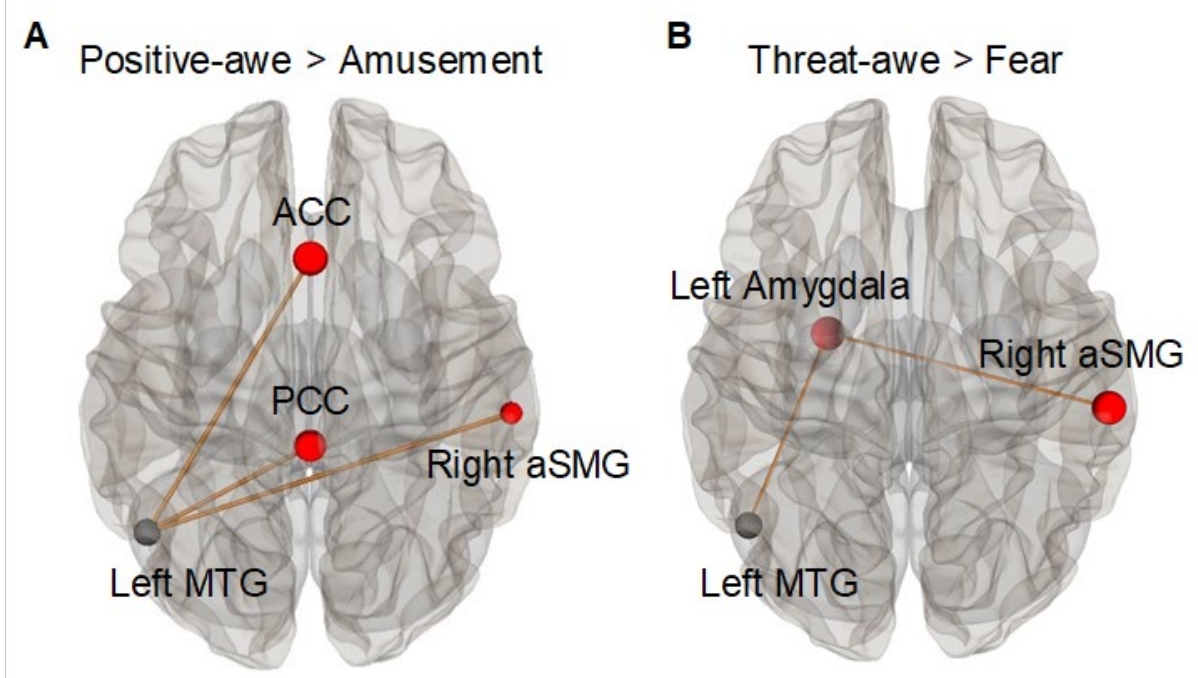

Figure 4. Functional connectivity (FC) differences between emotional conditions are shown. (A) FC between the left middle temporal gyrus (MTG) and anterior cingulate cortex (ACC), posterior 
cingulate cortex (PCC), and right anterior supramarginal gyrus (aSMG) was increased in the positive-awe condition relative to that in the amusement condition. (B) FC between the left MTG and left amygdala, and between the left amygdala and right aSMG, was increased in the threatawe condition relative to that in the fear condition. With the exception of left MTG-right aSMG FC ( $p<0.05$, uncorrected), all FCs are significant ( $p<0.05$, FDR corrected). Please refer to the online article for the color version of this figure. 


\section{Discussion}

The present study is the first to focus on brain function during the experience of two types of awe (positive- and threat-awe), and reveals neural mechanisms that are common or distinct to the type of awe. We found that left MTG deactivation serves as a common neural mechanism. We also identified distinct neural mechanisms, whereby FCs between the MTG and the ACC, PCC, and right aSMG are associated with positive-awe experiences, whilst MTGamygdala, and amygdala-aSMG FCs are associated with threat-awe experiences.

In both the positive- and threat-awe conditions, we observed a decreased activation of the left MTG relative to that in the amusement and fear conditions, which indicates that left MTG deactivation is common to the experience of both types of awe. This result is in line with the findings of Guan et al. (2018), in which dispositional awe was negatively correlated with gray matter volume in the left MTG. Several recent studies have demonstrated that awe is elicited by information-rich stimuli (e.g., panoramic nature and works of art), and increases self-diminishing attention (Keltner \& Haidt, 2003; Shiota et al., 2007). Furthermore, the theoretical framework of awe suggests two core features: perceptual vastness and the need for accommodation (e.g., Keltner and Haidt, 2003). Thus, our findings suggest that the left MTG plays a role in "schemaliberation" processes of awe, since it has been implicated in matching "existing schemas" to events (Davey et al., 2016), as well as in detecting and resolving incongruity during humor comprehension (Bartolo et al., 2006). Taken together, the present findings expand the theoretical understanding of awe to include a mechanism by which awe experiences induce the adaptation of a schema that no longer exists to fit the perception of current events.

Interestingly, the left MTG's activation level was low in the positive-awe condition in contrast to the threat-awe condition. This result is consistent with previous studies demonstrating 
different functions of positive- and threat-awe in terms of self-related processes (i.e., not injurious to one's self-worth and accompanying negative feelings of the self, respectively) (Gordon et al., 2017; Piff et al., 2015). Given that positive-awe increases the tolerance of others' norm violations, while threat-awe does not (Sawada \& Nomura, 2020), in our study, the differential deactivation on MTG within awe suggests that positive-awe might liberate one's selfschema more flexibly, while threat-awe might not or might perform this function to a lesser degree.

Importantly, our findings would also have contributions to the understandings of the emotional uniqueness of awe. For example, awe is differentiated from surprise caused by temporary unpredicted events that do not require effortful assimilation (Valdesolo, Shtulman, \& Baron, 2017). In addition, as some researches indicate that awe is triggered by an entity that is vast and challenges one's worldview (e.g., Stellar et al., 2017), our results suggest that higher levels of schema (e.g., worldviews, values) might be liberated through experiencing awe. Future research should investigate whether and how the neural processes of awe are different from those of surprise.

It also should be noted that our findings would have implications for neuroaesthetic researches. Another research investigating neural correlations of awe, which did not focus on threat-awe, indicated that the default mode network (DMN), which has been thought to be associated with self-reflective thought, was less activated during positive-awe experiences (van Elk, Gomez, Zwaag, Schie, \& Sauter, 2019). Conversely, the DMN were positively activated during trials in which the artworks were highly-rated, suggesting that certain artworks can "resonate" with an individual's sense of self in terms of neuroaesthetics (Vessel, Starr, \& Rubin, 2013). Thus, to the decision to engage in self-related processing might distinguish aesthetic 
experiences from positive-awe experiences, which is consistent with our results that awe might involve schema-liberation processes. Although our study did not aim to investigate the relationship between awe experiences and the $\mathrm{DMN}$, our findings encourage further investigation of neural networks including DMN during awe experiences in comparison to aesthetic experiences.

Specific responses that occurred during positive-awe experiences included increased FC between the left MTG and the ACC and PCC relative to that in the amusement condition. Positive-awe enhances the tendency to perceive intention and human agency in random events (Valdesolo \& Graham, 2014). For example, watching clips of nature induces a decreased tolerance for uncertainty, which, in turn, increases the tendency to infer the hand of human agency in random numerical patterns. Our findings suggest that there might be psychological processes that enable humans to find resolution and meaning in unprecedented experiences by liberating existing schemas.

In addition, considering the fact that positive-awe experiences often cause an aesthetic perception (Silvia et al., 2015), the present results are consistent with evidence that both the ACC and PCC are associated with reward-related processes during aesthetic experiences (Kawabata \& Zeki, 2003; Yeh, Lin, Hsu, Kuo, \& Chen, 2015). Previous studies have indicated that positiveawe, in contrast to threat-awe, improves subjective well-being and stress-related symptoms (Gordon et al., 2017; Rudd, Vohs, \& Aaker, 2012). This effect is not only momentary, but remains one week later (Anderson, Monroy, and Keltner, 2018). Therefore, positive-awe experiences are not limited to temporary reward processes, but might have more abstract and cathartic effects that involve MTG-ACC FC. 
Interestingly, threat-awe experiences increased the FC between the left MTG and amygdala relative to that in the fear condition. The amygdala is involved in the rapid processing of relevant stimuli, allowing fast responses (Cunningham \& Brosch, 2012). For example, the amygdala is associated with decreased reaction times to a target face after subliminal priming with an angry face (Nomura et al., 2004) and increased response bias (referred to as a "framing effect”) during a decision-making task (De Martino, Kumaran, Seymour, \& Dolan, 2006). Thus, the amygdala is involved in rapid decision-making and behavioral responses. It is also widely known that similar responses result from time pressure (e.g., Evans and Stanovich, 2013), such that awe-related phenomena cause reductions in the time to display helping behaviors toward strangers during threat-awe experiences (Guan, Chen, Chen, Liu, \& Zha, 2019).

Importantly, the right aSMG was functionally connected with the left MTG during positive-awe experiences (however, the significance threshold was uncorrected). The right aSMG is a part of the TPJ that integrates information regarding self and others (Ionta et al., 2011), and is associated with empathic responses to others' pain (Luo et al., 2015). Positive-awe experiences increase a feeling of spirituality and a connection with the world or with others (Shiota et al., 2007; Van Cappellen \& Saroglou, 2012). Therefore, the present results suggest that positive-awe experiences may blur self-other boundaries via right aSMG involvement. On the other hand, the SMG was co-activated with the amygdala during threat-awe experiences. Threat stimuli, such as death and disease, increase amygdala activity and generally increase in-group favoritism and out-group derogation (Jonas et al., 2014). Although the right SMG, which is located in an anterior part of the TPJ, plays a role in metalizing, the right TPJ is associated with various sympathetic responses, depending on whether the target is an in-group or out-group member (Cheon et al., 2011; Luo et al., 2015; Rilling, Dagenais, Goldsmith, Glenn, \& Pagnoni, 
2008). Therefore, the present results suggest that, during threat-awe experiences, the right aSMG promotes subsequent defensive behaviors by coordinating with the amygdala.

Our research extends the study of awe from evolutionary perspectives by investigating specific neutral mechanisms of threat-awe. Current results suggest that threat-awe experiences involve the amygdala, which is a part of the primary structures within the limbic system. Theoretically, the threatening variant of awe, which is referred to as primordial awe, and from which other variants emerged, has evolved into an emotional reaction towards high-ranking leaders, motivating patterns of cognition, and into an action that can enable lower-ranked individuals subordinate their self-interest and conform into the social hierarchies of the groups to which they belong (Gordon et al., 2017; Keltner \& Haidt, 2003; Weber, 1968). In addition, residents of areas prone to natural disasters (e.g., Japan or China) have higher tendencies to experience the negative side of awe, suggesting that threat-awe experiences motivate people to connect with others in interdependent contexts in order to alleviate negative emotions (Nomura, Tsuda, \& Rappleye, in press). Thus, our findings might explain the processes of how historical or cultural differences of awe have emerged.

It is worth noting several limitations of the present study, as well as the directions for future research. Since our awe stimuli mainly comprised scenes of nature, it is important to examine whether the results can be generalized to other awe-inspiring stimuli, such as great achievements of others. In addition, as a previous study on daily awe experiences demonstrated that self-relevant experiences are a common source of awe for participants in the United States but not for Chinese participants (Bai et al., 2017), future work should consider variations in the sources of awe between individualistic and collectivist cultures. Nevertheless, current research offers important insights into social functions of emotions (e.g., Keltner \& Haidt, 1999). Future 
research should focus on similar and different neural mechanisms between awe and other selftranscendent emotions (e.g., compassion, gratitude).

In conclusion, the present study is the first to reveal common and distinct neural mechanisms associated with positive- and threat-awe. Our findings provide neural evidence that may have demonstrable behavioral implications for social cognition. Understanding the neural basis of awe expands our knowledge regarding the socio-cognitive mechanisms underlying the recognition of the "self" and "others" in humans. 


\section{References}

Anderson, C. L., Monroy, M., \& Keltner, D. (2018). Awe in nature heals: Evidence from military veterans, at-risk youth, and college students. Emotion, 18, 1195. https://doi.org/10.1037/emo0000442

Bai, Y., Maruskin, L. A., Chen, S., Gordon, A. M., Stellar, J. E., McNeil, G. D., ... \& Keltner, D. (2017). Awe, the diminished self, and collective engagement: Universals and cultural variations in the small self. Journal of Personality and Social Psychology, 113, 185. https://doi.org/10.1037/pspa0000087

Breukelaar, I. A., Williams, L. M., Antees, C., Grieve, S. M., Foster, S. L., Gomes, L., \& Korgaonkar, M. S. (2018). Cognitive ability is associated with changes in the functional organization of the cognitive control brain network. Human Brain Mapping, 39, 50285038. https://doi.org/10.1002/hbm.24342

Bartolo, A., Benuzzi, F., Nocetti, L., Baraldi, P., \& Nichelli, P. (2006). Humor comprehension and appreciation: an FMRI study. Journal of Cognitive Neuroscience, 18, 1789-1798. https://doi.org/10.1162/jocn.2006.18.11.1789

Campos, B., Shiota, M. N., Keltner, D., Gonzaga, G. C., \& Goetz, J. L. (2013). What is shared, what is different? Core relational themes and expressive displays of eight positive emotions. Cognition \& Emotion, 27, 37-52. https://doi.org/10.1080/02699931.2012.683852

Cheon, B. K., Im, D. M., Harada, T., Kim, J. S., Mathur, V. A., Scimeca, J. M., ... \& Chiao, J. Y. (2011). Cultural influences on neural basis of intergroup empathy. NeuroImage, 57, 642650. https://doi.org/10.1016/j.neuroimage.2011.04.031 
Cunningham, W. A., \& Brosch, T. (2012). Motivational salience: Amygdala tuning from traits, needs, values, and goals. Current Directions in Psychological Science, 21, 54-59. https://doi.org/10.1177/0963721411430832

Davey, J., Cornelissen, P. L., Thompson, H. E., Sonkusare, S., Hallam, G., Smallwood, J., \& Jefferies, E. (2015). Automatic and controlled semantic retrieval: TMS reveals distinct contributions of posterior middle temporal gyrus and angular gyrus. Journal of Neuroscience, 35, 15230-15239. https://doi.org/10.1523/JNEUROSCI.4705-14.2015

Davey, J., Thompson, H. E., Hallam, G., Karapanagiotidis, T., Murphy, C., De Caso, I., ... \& Jefferies, E. (2016). Exploring the role of the posterior middle temporal gyrus in semantic cognition: Integration of anterior temporal lobe with executive processes. NeuroImage, 137, 165-177. https://doi.org/10.1016/j.neuroimage.2016.05.051

De Martino, B., Kumaran, D., Seymour, B., \& Dolan, R. J. (2006). Frames, biases, and rational decision-making in the human brain. Science, 313, 684-687. https://doi.org/10.1126/science.1128356

Decety, J., \& Sommerville, J. A. (2003). Shared representations between self and other: a social cognitive neuroscience view. Trends in Cognitive Sciences, 7, 527-533. https://doi.org/10.1016/j.tics.2003.10.004

Evans, J. S., \& Stanovich, K. E. (2013). Dual-process theories of higher cognition: Advancing the debate. Perspectives on Psychological Science, 8, 223-241. https://doi.org/10.1177/1745691612460685

Gordon, A. M., Stellar, J. E., Anderson, C. L., McNeil, G. D., Loew, D., \& Keltner, D. (2017). The dark side of the sublime: Distinguishing a threat-based variant of awe. Journal of Personality and Social Psychology, 113, 310. https://doi.org/10.1037/pspp0000120 
Guan, F., Chen, J., Chen, O., Liu, L., \& Zha, Y. (2019). Awe and prosocial tendency. Current Psychology, 1-9. https://doi.org/10.1007/s12144-019-00244-7

Guan, F., Xiang, Y., Chen, O., Wang, W., \& Chen, J. (2018). Neural basis of dispositional awe. Frontiers in Behavioral Neuroscience, 12, 209. https://doi.org/10.3389/fnbeh.2018.00209 Hayden, B. Y., \& Platt, M. L. (2009) Cingulate Cortex. In: Squire, L. R., (ed.) Encyclopedia of Neuroscience, volume 2, pp. 887-892. Oxford: Academic Press.

Immordino-Yang, M. H., McColl, A., Damasio, H., \& Damasio, A. (2009). Neural correlates of admiration and compassion. Proceedings of the National Academy of Sciences, 106, 8021-8026. https://doi.org/10.1073/pnas.0810363106

Ionta, S., Heydrich, L., Lenggenhager, B., Mouthon, M., Fornari, E., Chapuis, D., ... \& Blanke, O. (2011). Multisensory mechanisms in temporo-parietal cortex support self-location and first-person perspective. Neuron, 70, 363-374. https://doi.org/10.1016/j.neuron.2011.03.009

Jonas, E., McGregor, I., Klackl, J., Agroskin, D., Fritsche, I., Holdbrook, C., . . Quirin, M. (2014). Threat and defense: From anxiety to approach. In J. M. Olson \& M. P. Zanna (Eds.), Advances in Experimental Social Psychology (Vol. 49, pp. 219-286). San Diego, CA: Academic Press.

Kawabata, H., \& Zeki, S. (2004). Neural correlates of beauty. Journal of Neurophysiology, 91, 1699-1705. https://doi.org/10.1152/jn.00696.2003

Keltner, D., \& Haidt, J. (1999). Social functions of emotions at four levels of analysis. Cognition \& Emotion, 13, 505-521. https://doi.org/ 10.1080/026999399379168

Keltner, D., \& Haidt, J. (2003). Approaching awe, a moral, spiritual, and aesthetic emotion. Cognition and Emotion, 17, 297-314. https://doi.org/10.1080/02699930302297 
Levy, D. J., \& Glimcher, P. W. (2011). Comparing apples and oranges: using reward-specific and reward-general subjective value representation in the brain. Journal of Neuroscience, 31, 14693-14707. https://doi.org/10.1523/JNEUROSCI.2218-11.2011.

Lindquist, K. A., Wager, T. D., Kober, H., Bliss-Moreau, E., \& Barrett, L. F. (2012). The brain basis of emotion: a meta-analytic review. Behavioral and Brain Sciences, 35, 121. https://doi.org/10.1017/S0140525X11000446

Luo, S., Ma, Y., Liu, Y., Li, B., Wang, C., Shi, Z., ... \& Han, S. (2015). Interaction between oxytocin receptor polymorphism and interdependent culture values on human empathy. Social Cognitive and Affective Neuroscience, 10, 1273-1281. https://doi.org/10.1093/scan/nsv019

Muto, S. (2014). The concept structure of respect-related emotions in Japanese university students. Shinrigaku kenkyu: The Japanese journal of psychology, 85, 157-167. https://doi.org/10.4992/jjpsy.85.13021

Nomura, M., Ohira, H., Haneda, K., Iidaka, T., Sadato, N., Okada, T., \& Yonekura, Y. (2004). Functional association of the amygdala and ventral prefrontal cortex during cognitive evaluation of facial expressions primed by masked angry faces: an event-related fMRI study. NeuroImage, 21, 352-363. https://doi.org/10.1016/j.neuroimage.2003.09.021

Nomura, M., Tsuda, A., Rappleye, J. (in press). Defining awe in East Asia: Cultural differences in describing the emotion and experience of awe. In Chiao, J, Shu-Chen, Rebecca, Bob (eds.), Handbook of Cultural Neuroscience: Cultural Neuroscience and Health. New York: Oxford University Press.

Öhman, A. (2005). The role of the amygdala in human fear: automatic detection of threat. Psychoneuroendocrinology, 30, 953-958. https://doi.org/10.1016/j.psyneuen.2005.03.019 
Piff, P. K., Dietze, P., Feinberg, M., Stancato, D. M., \& Keltner, D. (2015). Awe, the small self, and prosocial behavior. Journal of Personality and Social Psychology, 108, 883. https://doi.org/10.1037/pspi0000018

Pozzi, E., Bousman, C. A., Simmons, J. G., Vijayakumar, N., Schwartz, O., Seal, M., ... \& Whittle, S. L. (2019). Interaction between hypothalamic-pituitary-adrenal axis genetic variation and maternal behavior in the prediction of amygdala connectivity in children. NeuroImage, 197, 493-501. https://doi.org/10.1016/j.neuroimage.2019.05.013

Rilling, J. K., Dagenais, J. E., Goldsmith, D. R., Glenn, A. L., \& Pagnoni, G. (2008). Social cognitive neural networks during in-group and out-group interactions. NeuroImage, 41, 1447-1461. https://doi.org/10.1016/j.neuroimage.2008.03.044

Rodrigues, S. M., LeDoux, J. E., \& Sapolsky, R. M. (2009). The influence of stress hormones on fear circuitry. Annual Review of Neuroscience, 32, 289-313. https://doi.org/10.1146/annurev.neuro.051508.135620

Rudd, M., Vohs, K. D., \& Aaker, J. (2012). Awe expands people's perception of time, alters decision making, and enhances well-being. Psychological Science, 23, 1130-1136. https://doi.org/10.1177/0956797612438731

Sawada, K., \& Nomura, M. (2020). Influence of Positive and Threatened Awe on the Attitude Toward Norm Violations. Frontiers in Psychology, 11, 148. https://doi.org/10.3389/fpsyg.2020.00148

Schaefer, A., Nils, F., Sanchez, X., \& Philippot, P. (2010). Assessing the effectiveness of a large database of emotion-eliciting films: A new tool for emotion researchers. Cognition and Emotion, 24, 1153-1172. https://doi.org/10.1080/02699930903274322 
Shiota, M. N., Keltner, D., \& John, O. P. (2006). Positive emotion dispositions differentially associated with Big Five personality and attachment style. The Journal of Positive Psychology, 1, 61-71. https://doi.org/10.1080/17439760500510833

Shiota, M. N., Keltner, D., \& Mossman, A. (2007). The nature of awe: Elicitors, appraisals, and effects on self-concept. Cognition and Emotion, 21, 944-963. https://doi.org/10.1080/02699930600923668

Silvia, P. J., Fayn, K., Nusbaum, E. C., \& Beaty, R. E. (2015). Openness to experience and awe in response to nature and music: Personality and profound aesthetic experiences. Psychology of Aesthetics, Creativity, and the Arts, 9, 376. https://doi.org/10.1037/aca0000028

Stellar, J. E., Gordon, A. M., Piff, P. K., Cordaro, D., Anderson, C. L., Bai, Y., ... \& Keltner, D. (2017). Self-transcendent emotions and their social functions: Compassion, gratitude, and awe bind us to others through prosociality. Emotion Review, 9, 200-207. https://doi.org/10.1177/1754073916684557

Straube, T., Preissler, S., Lipka, J., Hewig, J., Mentzel, H. J., \& Miltner, W. H. (2010). Neural representation of anxiety and personality during exposure to anxiety-provoking and neutral scenes from scary movies. Human Brain Mapping, 31, 36-47. https://doi.org/10.1002/hbm.20843.

Valdesolo, P., \& Graham, J. (2014). Awe, uncertainty, and agency detection. Psychological Science, 25, 170-178. https://doi.org/10.1177/0956797613501884

Valdesolo, P., Shtulman, A., \& Baron, A. S. (2017). Science is awe-some: The emotional antecedents of science learning. Emotion Review, 9, 215-221. https://doi.org/10.1177/1754073916673212 
Van Cappellen, P., \& Saroglou, V. (2012). Awe activates religious and spiritual feelings and behavioral intentions. Psychology of Religion and Spirituality, 4, 223. https://doi.org/10.1037/a0025986

van Elk, M., Arciniegas Gomez, M. A., van der Zwaag, W., van Schie, H. T., \& Sauter, D. (2019). The neural correlates of the awe experience: Reduced default mode network activity during feelings of awe. Human Brain Mapping. https://doi.org/10.1002/hbm.24616

Vessel, E. A., Starr, G. G., \& Rubin, N. (2013). Art reaches within: aesthetic experience, the self and the default mode network. Frontiers in Neuroscience, 7, 258. https://doi.org/10.3389/fnins.2013.00258

Weber, M. (1968). Economy and society. New York, NY: Bedminster Press Incorporated. Whalen, P. J. (2007). The uncertainty of it all. Trends in Cognitive Sciences, 11, 499-500. https://doi.org/10.1016/j.tics.2007.08.016

Wierzba, M., Riegel, M., Wypych, M., Jednoróg, K., Grabowska, A., \& Marchewka, A. (2018). Cognitive control over memory-individual differences in memory performance for emotional and neutral material. Scientific Reports, 8, 3808. https://doi.org/10.1038/s41598-018-21857-1

Whitfield-Gabrieli, S., \& Nieto-Castanon, A. (2012). Conn: a functional connectivity toolbox for correlated and anticorrelated brain networks. Brain Connectivity, 2, 125-141. https://doi.org/10.1089/brain.2012.0073

Yeh, Y. C., Lin, C. W., Hsu, W. C., Kuo, W. J., \& Chan, Y. C. (2015). Associated and dissociated neural substrates of aesthetic judgment and aesthetic emotion during the 
appreciation of everyday designed products. Neuropsychologia, 73, 151-160.

https://doi.org/10.1016/j.neuropsychologia.2015.05.010 